\title{
As Exportações da Região Sul do Brasil: Uma Análise do Setor Agropecuário
}

\author{
Daniel Claudy da Silveira \\ Universidade Regional do Noroeste do Estado do Rio Grande do Sul - ljuí - Rio \\ Grande do Sul - Brasil \\ Paulo Ricardo Feistel \\ Universidade Federal de Santa Maria - Santa Maria - Rio Grande do Sul - Brasil \\ Argemiro Luís Brum \\ Universidade Regional do Noroeste do Estado do Rio Grande do Sul - ljuí - Rio \\ Grande do Sul - Brasil
}

\begin{abstract}
Resumo
Este artigo tem o objetivo analisar os fluxos de comércio dos principais produtos do setor agropecuário (soja, fumo e carnes) exportados pela Região Sul do Brasil, a seus principais mercados de destino (Argentina, China, Estados Unidos e União Europeia), através de um modelo gravitacional, por estimação de dados em painel, com a abordagem de mínimos quadrados ordinários (MQO-Pooled), no período de 2000 a 2012. A estimação do modelo gravitacional apresentou resultados que seguem as estimativas dos trabalhos seminais da literatura econômica. No mesmo se demonstra que, no período analisado, os fluxos do setor agropecuário da Região Sul sofrem influência negativa da distância entre os países e, por outro lado, positivamente em relação à massa populacional e a taxa de câmbio real sobre os fluxos comerciais entre os países considerados.
\end{abstract}

Palavras-chave: Exportações agropecuárias. Modelo gravitacional. Região Sul do Brasil.

The Exports of the Southern Region of Brazil: An Analysis of the Agricultural Sector

\section{Abstract}

This article aims to analyze the trade flows of the main products of the agricultural sector (soybean, tobacco and meat) exported by the Southern Region of Brazil, its main target market (Argentina, China, United States and European Union), through a gravitational model, estimation of panel data, with the approach of ordinary least squares (OLS Pooled), from 2000 to 2012. The estimation of the gravity model results showed that the estimates follow the seminal works of economic literature. The same is shown that, in the analyzed period, the flow of the agricultural sector of the Southern Region suffer negative influence of the distance between countries and, on the other hand, positively in relation to the mass population and the real exchange rate on trade flows between countries considered.

Keywords: Agricultural exports. Gravity model. Southern Brazil. 


\title{
Exportaciones de la Región del Sur de Brasil: un Análisis del Sector Agrícola
}

\begin{abstract}
Resumen
Este documento tiene como objetivo analizar los flujos comerciales de los principales productos del sector agrícola (soja, tabaco y carne) exportados por la Región Sur de Brasil, a sus principales mercados de destino (Argentina, China, Estados Unidos y la Unión Europea), a través de un modelo gravitacional, mediante la estimación de datos de panel, utilizando el enfoque de mínimos cuadrados ordinarios (MQO - pooled), de 2000 a 2012. La estimación del modelo gravitacional presentó resultados que siguen las estimaciones de los trabajos fundamentales de la literatura económica. En el mismo período, se muestra que, durante el período analizado, los flujos del sector agrícola de la Región Sur están influenciados negativamente por la distancia entre países y, por otro lado, positivamente en relación con la masa de la población y el tipo de cambio real de los flujos comerciales entre los países considerados.
\end{abstract}

Palabras clave: Exportaciones agrícolas. Modelo gravitacional. Región sur de Brasil.

\section{Introdução}

A partir de meados da década de 1980 as exportações totais e agrícolas no mundo cresceram em ritmo mais acelerado. Isso revela que houve um aumento da interdependência comercial entre as economias dos diferentes países. Enquanto o valor real (descontada a inflação) das exportações agrícolas dos países desenvolvidos expandiu-se a uma taxa anual de 4,2\%, o dos países em desenvolvimento cresceu a uma taxa bem menor, de 2,1\% ao ano. Na década de 1990 tal situação mudou, com o valor real das exportações agrícolas dos países desenvolvidos crescendo $2,0 \%$ ao ano e o dos países em desenvolvimento aumentando 3,0\% ao ano. O valor real das exportações agrícolas mundiais registrou diminuição em sua expansão entre as décadas de 1980 e 1990, com a taxa anual de crescimento passando de $3,4 \%$ para $2,4 \%$. Muito provavelmente, esse fato não esteve associado à diminuição da taxa de crescimento da quantidade exportada, mas à redução de preços agropecuários verificada no final dos anos 1990 (FAO, 2005).

De acordo com dados da FAO (2013), na década de 2000, quando os preços das commodities se elevaram, o valor real das exportações agropecuárias cresceu a uma taxa de $8,3 \%$ ao ano. Em valores absolutos passou de US\$ 403,0 bilhões, em 2000, para US\$ 818,0 bilhões, em 2010. As regiões dos países desenvolvidos (América do Norte, Europa Ocidental e Oceania) perderam importância nas exportações mundiais na década de 2000, com exceção do açúcar e derivados e, dos lácteos, no caso da América do Norte. Já entre as regiões de países em desenvolvimento, tanto a África quanto a Ásia perderam participação no comércio mundial (com exceção, na África, aos cereais e, na Ásia, aos lácteos). A Ásia revela maior importância que a África nas exportações mundiais e ambos os continentes têm se caracterizado por serem importadores líquidos de produtos agropecuários.

A América Latina e Caribe aumentaram sua presença nas exportações agropecuárias mundiais, revelando grande participação em 2010, especialmente nos casos do açúcar e derivados, carnes e oleaginosas, com destaque para a soja. Entre os países dessa região, os maiores exportadores são a Argentina e, especialmente, 
o Brasil. Esse último país demonstrou muito dinamismo no caso das oleaginosas (soja), açúcar e derivados, carnes e tabaco. A expansão da quantidade exportada entre 2000 e 2010 de cereais foi de $24,4 \%$, das oleaginosas de 79,5\%, do açúcar e derivados de $42,5 \%$, e das carnes de $62,3 \%$. No mesmo período, o valor das exportações agropecuárias cresceu 103,0\%, puxado, em grande parte, pelo aumento dos preços no mercado internacional (FAO, 2013).

A Região Sul do Brasil, conforme dados da Secretaria de Comércio Exterior (SECEX), do Ministério do Desenvolvimento, Indústria e Comércio Exterior (MDIC), é responsável por $15 \%$ das exportações totais brasileiras, em 2012. O setor agropecuário (soja, carnes e tabaco) é responsável por $25 \%$ das exportações totais dessa Região, ou seja, por gerar US\$10,7 bilhões em divisas, em 2012. Em números absolutos, as exportações do setor agropecuário correspondem a aproximadamente US\$14,0 bilhões, ou 35\% das exportações totais. Particularmente, em 2000, a participação dos produtos nas exportações totais era de pouco mais de 19\%. Quanto aos destinos dessas exportações, são considerados os principais países importadores, tais como a Argentina, a China, os Estados Unidos e a União Europeia (Bloco Econômico composto por 27 países), no período analisado.

Neste âmbito, com a crescente importância do setor agroexportador da Região Sul brasileira no montante das exportações, faz sentido analisar os condicionantes e a sua dinâmica, levando em consideração os produtos soja, tabaco e carnes, os quais são cultivados e característicos desta Região. Os mesmos representam grande parte das exportações deste setor.

Para tal análise, segundo Piani e Kume (2000) e Azevedo e Reis (2006), um enfoque bastante utilizado nos últimos anos baseia-se na análise dos fluxos bilaterais de comércio por meio da "equação gravitacional”, pela qual é possível comparar o peso da influência de preferências comerciais com o de outros determinantes do comércio, como a proximidade geográfica dos países, seus níveis de renda absoluta e per capita. Tradicionalmente, esses modelos costumam gerar bons resultados empíricos, que têm sido apoiados por desenvolvimentos teóricos recentes, rigorosos e abrangentes.

Assim, o objetivo principal do presente trabalho é analisar os fluxos de comércio dos principais produtos do setor agropecuário (soja, tabaco e carnes) exportados pela Região Sul do Brasil, a seus principais mercados de destino (Argentina, China, Estados Unidos e União Europeia), os quais são responsáveis pelo montante de US\$10,7 bilhões em exportações destes produtos. Além disso, os mesmos detêm uma massa populacional conjunta de 2,2 bilhões de pessoas e um PIB integrado de US\$33,0 trilhões, o que de certa forma representa o tamanho do mercado destes países. Para isso, é estimado um modelo gravitacional, através de dados em painel, com a abordagem de mínimos quadrados ordinários (MQO Pooled), para o período de 2000 a 2012.

O trabalho está disposto da seguinte maneira: na primeira seção é apresentada a evolução do comércio agropecuário da região sul do Brasil; na seção dois uma revisão bibliográfica do modelo gravitacional e suas fundamentações teóricas; a terceira seção aborda a metodologia empregada para a realização do estudo; na quarta seção são demonstradas as análises e discussão dos resultados, seguida das notas finais. 


\section{Evolução Recente do Comércio Agropecuário da Região Sul do Brasil}

Esta seção resgata o período de expansão do comércio do Brasil e da Região Sul do Brasil com o Resto do Mundo, a partir da década de 2000, destacando a evolução das exportações agropecuárias até 2012. Com um ambiente bastante favorável na economia e relações comerciais internacionais, as exportações agropecuárias do Brasil, em particular, da Região Sul, aumentaram ao longo do período considerado, que de certo modo, foram proporcionados, por um grande aumento da demanda chinesa (especialmente, em relação ao aumento da procura pelo produto soja).

A Região Sul do Brasil no período considerado apresentou crescente evolução em suas exportações, demonstrando forte potencial de expansão no comércio internacional. Na Figura 01, demonstra-se que no período de 2000 a 2012 houve um crescimento nas exportações da Região em aproximadamente $240 \%$. Sendo que, grande parte das exportações é dependente do setor agropecuário, responsável por aproximadamente $35 \%$ das exportações totais.

Figura 1. Balança Comercial da Região Sul do Brasil - 2000 a 2012 - US\$1.000 FOB

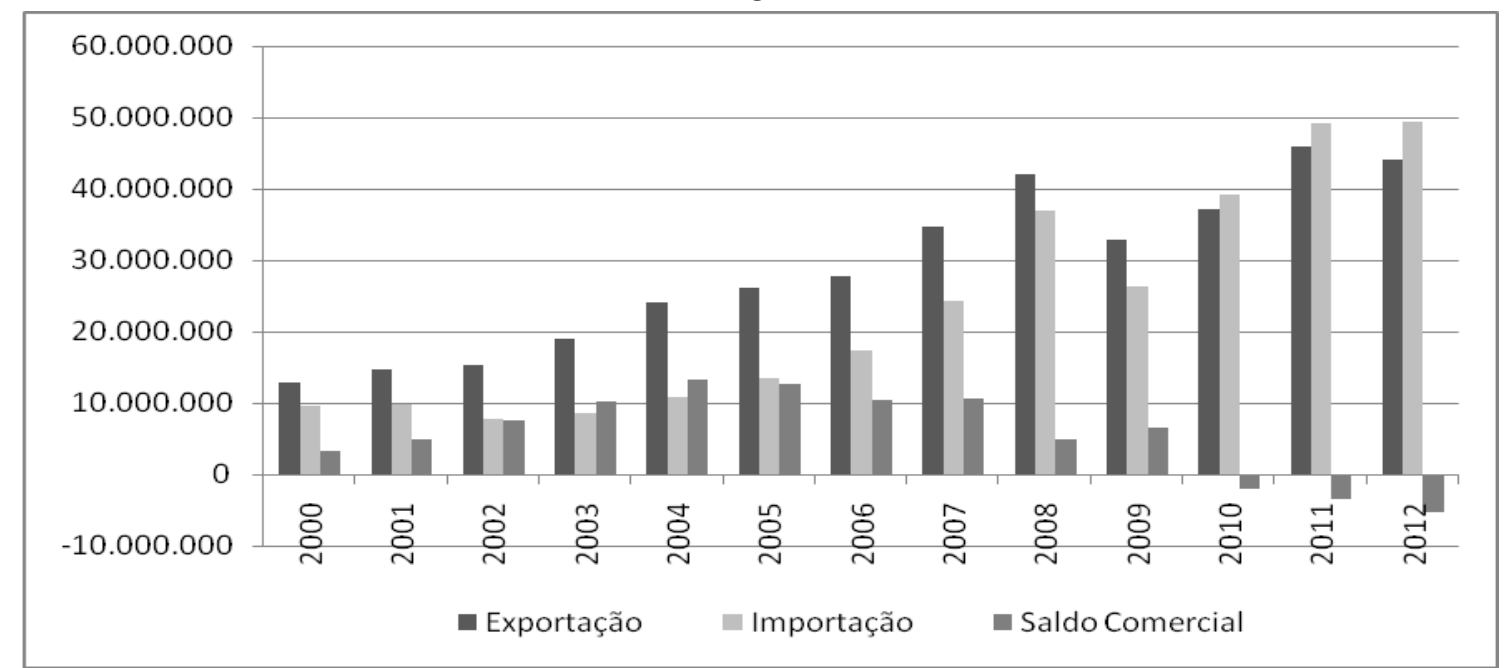

Fonte: SECEX/MDIC - Aliceweb.

As exportações do setor agropecuário da Região Sul do Brasil, tem forte peso sobre as exportações totais da região. Para ter-se ideia, de um total de exportações, na ordem de US\$ 44,0 bilhões em 2012, os produtos soja, carnes e tabaco foram responsáveis por US\$ 10,7 bilhões, ou seja, $25 \%$ das exportações totais desta região. Em termos de representatividade, em 2000, essa importância era de $19 \%$, demonstrando o crescimento deste setor no nível geral.

O produto soja, de acordo com dados da SECEX/MDIC, é responsável por US\$ 6,8 bilhões do montante de exportações, ou $64 \%$ do volume de exportações no ano de 2012, da Região Sul brasileira, considerando os produtos selecionados. Destes US\$ 6,8 bilhões, somente a China é responsável pela importação de US\$ 5,0 bilhões do produto soja. Já as exportações de carne representam um montante de US\$1,8 bilhão (16\%), sendo o maior importador a União Europeia, responsável por US\$1,3 bilhão de divisas e, o produto tabaco, que é responsável por US\$ 2,0 bilhões das 
exportações da Região Sul em 2012, representando 18\% do total, considerando os produtos selecionados, onde o principal país importador é a China (US\$ 1,2 bilhão).

Em relação ao montante monetário, representado na Figura 02, houve significativa expansão das exportações do setor agropecuário da Região Sul no período. Entre 2000 e 2012, tais exportações cresceram 335\%, evidenciando o forte potencial deste setor e a importância do mesmo para as contas externas da Região Sul. Vale ressaltar que, em termos agregados, a Região Sul no mesmo período, teve desempenho inferior ao do setor agropecuário, o qual ficou na ordem de $240 \%$ de crescimento das exportações totais.

Figura 2. Exportações do setor agropecuário da Região Sul do Brasil* - 2000/2012

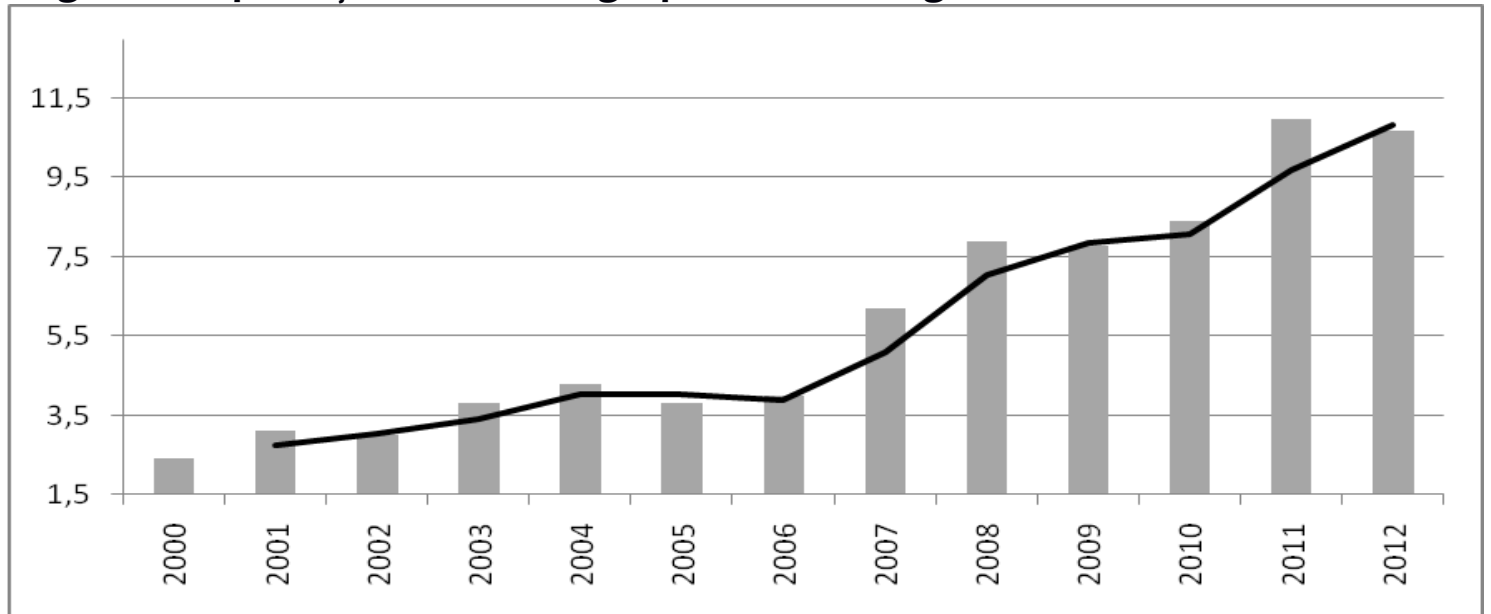

Fonte: SECEX/MDIC - Alice-web.

(*) Exportações agropecuárias da Região Sul do Brasil para a Argentina, China, Estados Unidos e União Europeia, considerando os produtos: carnes - dos capítulos 02 e 16 da Nomenclatura Comum do Mercosul (NCM - SH-2 dígitos); soja - capítulos 12 e 23; e, fumo - capítulo 24.

Os países selecionados (Argentina, China, Estados Unidos e União Europeia), então, são os responsáveis pela maior parte das exportações do setor agropecuário da Região Sul do Brasil. Tais países têm sua importância e tamanho no contexto da economia internacional e regional pela representatividade de seus produtos internos brutos e de sua massa populacional. O conjunto de países representa um montante monetário de US\$ 33,0 trilhões em 2012, enquanto que sua massa populacional integrada chega a 2,2 bilhões de pessoas (BANCO MUNDIAL, 2012). A China é responsável por uma massa populacional de 1,35 bilhão de pessoas, que por si só, demonstra o potencial mercado consumidor deste país, principalmente, nos gêneros alimentícios. 
Figura 3. Participação das Exportações do setor agropecuário em relação às exportações totais da Região Sul do Brasil* em \% - 2000 a 2012

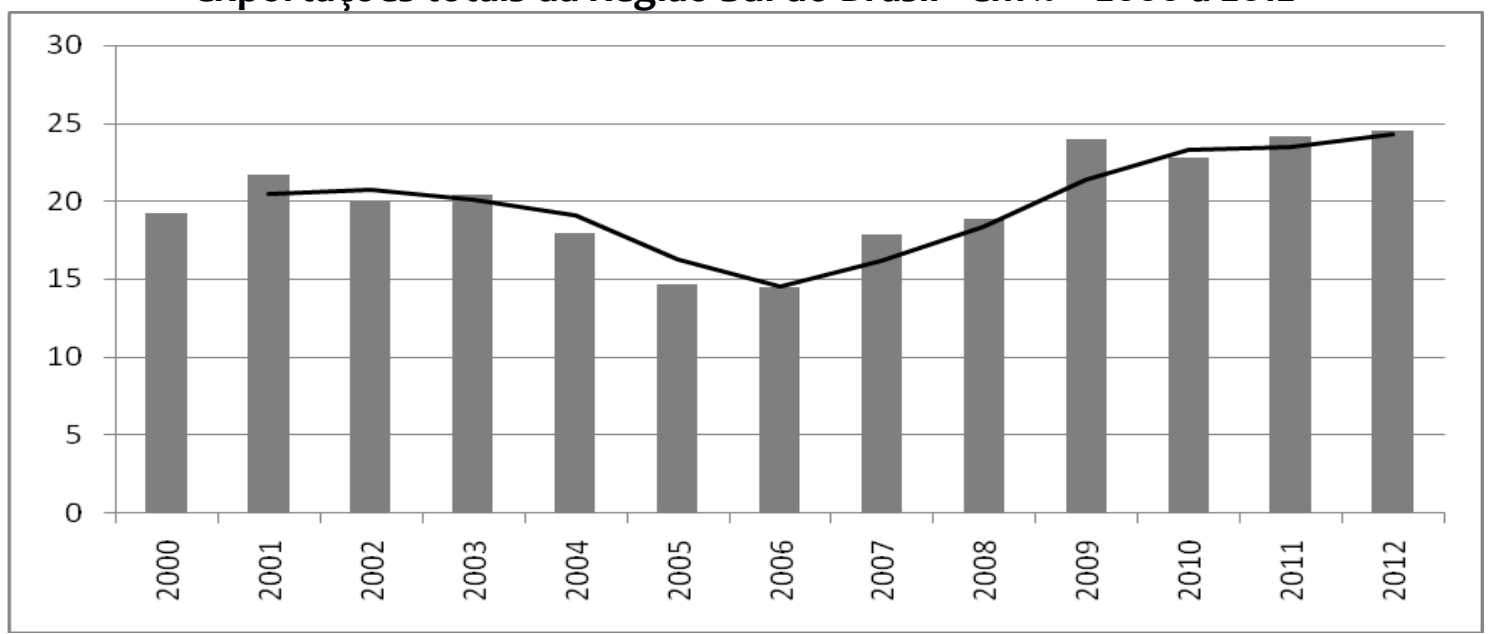

Fonte: SECEX/MDIC - Aliceweb.

(*) Exportações agropecuárias da Região Sul do Brasil para a Argentina, China, Estados Unidos e União Europeia, considerando os produtos: carnes - dos capítulos 02 e 16 da Nomenclatura Comum do Mercosul (NCM - SH-2 dígitos); soja - capítulos 12 e 23; e, fumo - capítulo 24.

Apesar de serem grandes importadores de produtos agropecuários, Argentina, China, Estados Unidos e União Europeia têm também na sua pauta exportadora os produtos agropecuários como fontes importantes de geração de divisas. No entanto, tais países (principalmente China, Estados Unidos e União Europeia), mesmo sendo grandes produtores e vendedores de produtos agropecuários, também são grandes importadores líquidos de inúmeros produtos que não por acaso encabeçam a lista de produtos efetivamente exportados pela Região Sul do Brasil. A diferença primordial reside no fato de haver vantagens na produção de determinados produtos e no emprego de tecnologia (qualidade, genética, melhoramentos, manejo, técnicas e pesquisa).

Quadro 1. Destino dos principais produtos do setor agropecuário da Região Sul do Brasil em 2012*

\begin{tabular}{|c|c|c|c|}
\hline Produto & $\mathbf{1}^{\mathbf{0}}$ principal & $\mathbf{2}^{\mathbf{0}}$ principal & $\mathbf{3}^{\mathbf{0}}$ principal \\
\hline Carnes e miudezas & União Europeia & China & Argentina \\
\hline Preparações de carnes & União Europeia & Argentina & Estados Unidos \\
\hline Sementes e oleaginosas & China & União Europeia & Argentina \\
\hline $\begin{array}{c}\text { Resíduos de indústrias } \\
\text { alimentares }\end{array}$ & União Europeia & Argentina & Estados Unidos \\
\hline $\begin{array}{c}\text { Fumo e seus sucedâneos } \\
\text { manufaturados }\end{array}$ & China & União Europeia & Estados Unidos \\
\hline
\end{tabular}

Fonte: SECEX/MDIC - Aliceweb

$\left(^{*}\right)$ Produtos exportados para os principais destinos, considerando-se: Argentina, China, Estados Unidos e União Europeia.

Quanto aos destinos, no Quadro 01, os principais países importadores dos produtos oriundos da Região Sul do Brasil, no que tange os produtos do setor agropecuário, conforme dados da SECEX/MDIC, do ano de 2012, são: a China (responsável por mais de 50,0\% das exportações), União Europeia (40,0\%), Argentina e Estados Unidos, que juntos representam aproximadamente 10,0\% das exportações de carnes - dos capítulos 02 e 16 da NCM/SH-2; soja - capítulos 12 e 23; 
e, fumo - capítulo 24. Os países citados representam 24,5\% das exportações totais da Região Sul do Brasil, conforme os produtos agropecuários considerados.

A Região Sul do Brasil, de acordo com os dados da SECEX/MDIC, tem um forte desempenho no que tange ao seu potencial exportador. O setor agropecuário da Região é responsável por $24,5 \%$ das exportações totais, ou US\$10,7 bilhões, de um montante total de US\$ 44,0 bilhões em exportações, no ano de 2012. O principal produto agropecuário exportado é a soja, representando mais de 45,0\% das exportações do setor em 2012. Em segundo, vêm as exportações de fumo (tabaco) e seus sucedâneos manufaturados, com cerca de US\$2,0 bilhões e, de resíduos de indústrias alimentares com o montante de US\$ 1,8 bilhão exportado.

Com o mercado internacional cada vez mais globalizado, e, com um maior estreitamento entre as relações de comércio entre os países, faz-se sentido enaltecer os fatores de atração das exportações agropecuárias sul-brasileira, para detectar as características dos parceiros comerciais que afetam as exportações dos produtos em questão e, de certo modo, avaliar o impacto de variáveis econômicas, locacionais e regionais sobre o desempenho da pauta agroexportadora da região de estudo e de seus parceiros.

Neste sentido, trata-se de entender o processo dinâmico das exportações do setor agropecuário da Região Sul do Brasil, a partir da realidade em questão, de modo a evidenciar quais foram às determinantes do montante exportável da Região e seus principais destinos de importação. Tal importância é assumida, pela forte dependência da economia frente às exportações de produtos agropecuários, que num âmbito regional, ainda é protagonista do desenvolvimento econômico da Região Sul brasileira.

\section{O Estado da Arte e Aplicações do Modelo Gravitacional}

Dentre os modelos aplicados às análises econômicas dos fluxos internacionais, o gravitacional pode ser considerado um dos mais amplamente usados e aceitos. Nos principais estudos realizados, que apresentam como objeto de estudo o modelo gravitacional, como dependente da renda e população e inversamente dependente da distância entre os países, destacam-se: Tinbergen (1962), Linnemann (1966), Leamer e Stern (1970), Aitken (1973), Anderson (1979), Bergstrand (1985 e 1989), Brada e Méndez (1985), Helpman (1987), Deardoff (1995) e McCallum (1995), que ao longo dos anos foram sendo aprimorados, incluindo-se novos parâmetros e fundamentos.

Num período posterior, novos métodos foram sendo implementados para a aplicação dos modelos de gravidade, onde se destacam os trabalhos de Bayoumi e Eichengreen (1995), Frankel, Stein e Wei (1995), Endoh (1999), Feenstra, Markusen e Rose (2001), Cheng e Wall (2002), Evenett e Keller (2002), Anderson e Van Wincoop (2003 e 2004), Mann e Otsuki (2004), Shepherd e Wilson (2008), Wilson (2004 e 2009) e Krugman e Obstfeld (2010).

Na segunda metade do século XX, Isard (1960), Tinbergen (1962), Linneman (1966), Leamer e Stern (1970), e Anderson (1979) perceberam que o volume de comércio entre dois países pode ser previsto, com razoável precisão, pela equação gravitacional. Dentro de um contexto teórico, para Coelho (1982, p. 02), a origem do modelo de interação espacial, ou modelos gravitacionais, encontra-se na analogia 
com a "Lei de Atração Gravitacional de Isaac Newton" que estabelece que a força da atração $F$ entre dois corpos de massas $m_{1}$ e $m_{2}$ é:

$$
F=G \frac{m m_{2}}{d^{2}}
$$

Em que $G$ é uma constante de atração gravitacional e $d$ a distância entre os dois corpos. Na aplicação deste conceito a interação espacial, a força de atração entre dois corpos é substituída pelo montante de interação entre duas zonas, enquanto que as massas dos corpos são substituídas por fatores de atração associados às zonas e, por sua vez, a função de atrito $F$ toma o lugar do fator de redução definida pelo inverso do quadrado da distância. Isto explica que os modelos de interação espacial sejam também chamados de modelos gravitacionais (COELHO, 1982, p. 02).

Em uma tentativa de conciliar a natureza especializada da teoria com o sucesso geral das aplicações empíricas, argumenta-se que uma grande variedade de teorias é consistente com a equação da gravidade. As teorias alternativas podem ser distinguidas por diferenças sutis nos valores dos parâmetros estimados. Eles começam com a diferenciação de produto (e, assim, completa especialização). No trabalho empírico, a distinção é vista no tamanho relativo das elasticidades das exportações. No caso de existir livre entrada, a elasticidade da exportação em relação à renda do exportador é maior do que aquela relativa à renda do importador. O contrário é verdadeiro se houver restrição à entrada. O trabalho empírico para bens diferenciados produziu resultados consistentes com as previsões teóricas do modelo de concorrência monopolística com livre entrada (FEENSTRA, MARKUSEN E ROSE, 2001).

Enfim, os países participam do comércio internacional por dois motivos básicos, e cada um deles contribui para seu ganho do comércio. Primeiro, eles comercializam entre si porque diferem uns dos outros. As nações, como os indivíduos, podem se beneficiar de suas diferenças, chegando a um arranjo em que cada uma produza as coisas que faz melhor (eficiência) em relação aos demais. Segundo, os países fazem comércio para obter economias de escala. Isto é, se cada um produz somente uma gama limitada de bens, pode produzir cada um desses bens em uma escala maior e, portanto, mais eficientemente do que se tentasse produzir tudo. No mundo real, os padrões do comércio internacional refletem a interação de ambos os motivos. 
Quadro 2. Fundamentos teóricos e conceitos principais no âmbito da utilização do modelo gravitacional em termos da ciência social e principalmente econômica

\begin{tabular}{|c|c|c|}
\hline Fundamentos Teóricos & Principais Conceitos & Principais Autores \\
\hline $\begin{array}{l}\text { Ciência social, espaço } \\
\text { regional e geografia } \\
\text { econômica. }\end{array}$ & $\begin{array}{c}\text { A mensuração das relações de } \\
\text { comércio intrarregional e sua } \\
\text { influência no comportamento das } \\
\text { unidades individuais. As regiões são } \\
\text { concebidas como potenciais } \\
\text { compradoras (ou como uma massa } \\
\text { potencial). }\end{array}$ & Isard (1960), Krugman (1991 e 1998). \\
\hline $\begin{array}{c}\text { Microeconomia } \\
\text { (maximização da utilidade, } \\
\text { teoria geral de equilíbrio, } \\
\text { preferências de Elasticidade } \\
\text { Constante de Susbstituição - } \\
\text { ECS). }\end{array}$ & $\begin{array}{l}\text { Um modelo usando a teoria da } \\
\text { gravidade poderia ser derivado de } \\
\text { uma função de maximização utilitária, } \\
\text { e teorias probabilísticas. }\end{array}$ & $\begin{array}{l}\text { Tinbergen (1962), Linnemann (1966), } \\
\text { Leamer e Stern (1970), Anderson } \\
\text { (1979), Bergstrand (1985 e 1989). }\end{array}$ \\
\hline $\begin{array}{l}\text { Teorias do Comércio } \\
\text { Internacional. }\end{array}$ & $\begin{array}{l}\text { Teorias do comércio diferem da } \\
\text { forma de especialização de produtos } \\
\text { que interferem no equilíbio: } 1 \text { ) } \\
\text { diferenças de tecnologia (modelo } \\
\text { Ricardiano); } 2 \text { ) dotações de } \\
\text { diferenças de fatores (modelo de } \\
\text { Hecksher-Ohlin); } 3 \text { ) modelos de } \\
\text { Retornos Crescentes de Escala (RCE). }\end{array}$ & $\begin{array}{c}\text { Tinbergen (1962), Linnemann (1966), } \\
\text { Anderson (1979), Bergstrand (1985), } \\
\text { Helpman (1987), Helpman e Krugman } \\
\text { (1985), McCallum (1995), Deadorff } \\
\text { (1995), Evenett e Keller (2002), } \\
\text { Anderson e Van Wincoop (2003 e } \\
\text { 2004). }\end{array}$ \\
\hline
\end{tabular}

Fonte: quadro adaptado de Pass (2002, p. 07).

Deste modo, considerações teóricas para explicar os fluxos de comércio internacional entre países e regiões têm sido amplamente discutidas e desenvolvidas por Tinbergen (1962); Linnemann (1966); Leamer e Stern (1970); Anderson (1979); Bergstrand (1985 e 1989); Helpman (1987); Deadorff (1995); McCallum (1995); Anderson e Wincoop (2003 e 2004), através da metodologia do modelo de gravidade. Apesar de contínuas discussões e incertezas sobre os fundamentos do modelo gravitacional, é possível dizer que estas considerações teóricas, as quais se dão principalmente com base em fundamentos microeconômicos e teorias de comércio, também são válidas para explorar as mudanças nos padrões de comércio internacional.

Conforme Pass (2002), o desenvolvimentodo e uso de equações de gravidade para os processos de modelagem econômica, com relação ao comércio internacional flui com base em várias considerações teóricas, o que pode ser explicado por três fundamentos teóricos principais (ver Quadro 02): a) ciência social, espaço regional e geografia econômica; b) fundamentos microeconômicos (maximização da utilidade, teoria geral de equilíbrio, preferências de elasticidade constantes de susbstituição), e; c) teorias do comércio internacional.

Este arcabouço teórico é utilizado pelos estudiosos em economia internacional para análise do padrão e o destino do comércio. O modelo padrão utilizado, através de uma abordagem econométrica, estabelece uma regularidade dos fluxos comerciais, os quais são relacionados positivamente com as rendas da origem e do destino e negativamente com a distância entre eles. Deste modo, quanto maior a renda dos países, maior a capacidade de comércio bilateral, mas, no entanto, a distância é inversamente proporcional a tal relação de comércio, ou seja, quanto maior a distância menor será o volume de comércio entre países. Esta 
premissa é transformada na forma de regressão ou modelo, sendo normalmente estimada numa equação logaritmíca, demonstrada a seguir:

$$
\ln X_{i j}=\alpha+\beta_{1} \ln Y_{i}+\beta_{2} \ln Y_{j}+\beta_{3} \ln D_{i j}
$$

Onde $X_{i j}$ é a exportação total do país i para o país j; $Y_{i}$ é a renda do país i; $Y_{j}$ é a renda do país j; e $D_{i j}$ é a distância entre o país i o país j.

Em níveis, o modelo assume a seguinte forma:

$$
X_{i j}=\frac{Y_{i}^{\beta_{1}} Y_{j}^{\beta_{2}}}{D_{i j}^{\beta_{2}}}
$$

Deste modo, tais modelos são conceituados na economia como equação da gravidade ou modelo gravitacional.

Anderson e Van Wincoop (2003) resolvem os termos de resistência em função das variáveis observáveis e estimam o modelo gravitacional por mínimos quadrados não-lineares para minimizar a soma dos quadrados dos erros. Porém, um método alternativo é substituir os termos de resistência multilateral por dummies para os países da amostra. Esse método leva a estimativas consistentes dos parâmetros do modelo e, sua principal vantagem, é que essas estimativas podem ser conduzidas com abordagem de Mínimos Quadrados Ordinários - MQO.

No que se refere aos custos de comercialização, o desenvolvimento teórico de Anderson e Van Wincoop (2003 e 2004) propõe que $t^{k}{ }_{i j}$ seja uma função loglinear de variáveis observadas, tais como a distância bilateral e outros fatores relacionados às barreiras comerciais entre as duas economias.

$$
\begin{aligned}
& \ln \left(X_{i j}^{k}\right)=\ln \left(E_{i}^{k}\right)+\ln \left(Y_{i}^{k}\right)-\ln \left(Y^{k}\right)+\left(1-\sigma_{k}\right) \ln \left(t_{i j}^{k}\right)-(1- \\
& \left.\alpha \sigma_{k}\right) \ln \left(P_{j}^{k}\right)- \\
& \left(1-\sigma_{k}\right) \ln \left(t_{i j}^{k}\right)- \\
& \left(1-\sigma_{k}\right) \ln \left(P_{j}^{k}\right)-\left(1-\sigma_{k}\right) \ln \left(\pi_{i}^{k}\right)
\end{aligned}
$$

Enfim, tal modelo teórico (Equação 04) desenvolvido por Anderson e Van Wincoop (2004) tem sido amplamente aceito na literatura relacionada à economia internacional, sendo utilizado como modelo padrão no desenvolvimento de estudos referentes à abordagem gravitacional.

O uso do modelo gravitacional para o estudo de questões de economia internacional no Brasil é relativamente recente e a aplicação do modelo gravitacional se dá para medir os efeitos de variáveis que afetam diretamente o volume de exportações, ou seja, que influenciam as relações bilaterais de comércio entre países ou regiões.

Os principais estudos realizados neste âmbito remetem a Hidalgo e Vergolino (1998), Reis e Crespo (1998), Carvalho e Negri (1999), Sá Porto (2000), Piani e Kume (2000), Castilho (2001), Burnquist et al. (2002), Paz e Franco Neto (2003), Maia (2003), Azevedo (2004, 2006, 2008 e 2013), Magalhães et al. (2004), Morais (2005), Magalhães e Domingues (2006), Fonseca e Hidalgo (2006), Silva et al. (2007), Mata e Freitas (2008), Salles et al. (2011), Burnquist e Souza (2011), Farias e Hidalgo (2012) e Cipolla (2013). 
Na próxima seção é apresentado o trabalho acerca do modelo de gravidade aplicado ao padrão de comércio das exportações agropecuárias, visando demonstrar as contribuições, estimativas e resultados das pesquisas realizadas. Para isso, é considerado o trabalho de Mata e Freitas (2008) - o qual é a base metodológica deste trabalho - bem como as aplicações mais recentes de Carvalho e Negri (1999), Castilho (2001), Burnquist et al. (2002), Wilson (2009) e Campos et. al (2012).

\section{Método de Análise}

Para realização deste estudo foi utilizado à abordagem do modelo econométrico gravitacional, considerando os principais trabalhos empíricos desenvolvidos pela literatura nacional e internacional. Os procedimentos econométricos utilizados, para o desenvolvimento do trabalho, seguiram a metodologia de dados em painel, pela abordagem de mínimos quadrados ordinários (MQO) considerando o modelo Pooled. Para a realização desta pesquisa será utilizado o Software STATA 10.1. Neste sentido, no que tange as exportações agropecuárias da Região Sul do Brasil, foram elencados os produtos: carnes - dos capítulos 02 e 16 (carnes e miudezas, e preparações de carnes) da Nomenclatura Comum do MERCOSUL (NCM), do Sistema Harmonizado (SH-2 dígitos); soja capítulos 12 e 23 (sementes e oleaginosas, e resíduos de indústrias alimentares), e; fumo - capítulo 24 (tabaco e seus sucedâneos manufaturados) para os países destino Argentina, China, Estados Unidos da América e União Europeia (Bloco Econômico composto por 27 países), sendo gerado um painel, com dados agrupados, conjuntamente com o método anteriormente descrito.

O modelo que será utilizado para o desenvolvimento do trabalho, será baseado na pesquisa de Mata e Freitas (2008, p. 268-269), que aplicaram um estudo para discutir os fatores de atração do montante das exportações agropecuárias brasileiras, sendo usadas as mesmas variáveis elencadas pelos autores. Neste sentido, o modelo parte de uma função Cobb-Douglas na sua expressão convencional:

$$
F_{i j}=\propto_{0} \cdot \prod_{k=1}^{n} X_{k}^{a_{k}} \cdot e^{u_{i j}}
$$

$\mathrm{Na}$ equação, tem-se que: $F_{i j}$ são os fluxos comerciais da economia i para a economia $j ; X_{k}$ são as variáveis explicativas; $\alpha_{0}$ é a constante; $\alpha_{k}$ são os parâmetros do modelo; $n$ é o número de variáveis explicativas e $u_{i j}$ é o termo errático com as hipóteses do modelo clássico de regressão.

A equação acima pode ser traduzida em uma regressão log-linear, que é linear nos parâmetros, linear nos logs das variáveis $F$ e $X^{9}$, e pode ser estimada pelo método dos mínimos quadrados ordinários (MQO). Nesses termos, para os propósitos da presente análise, tem-se a equação (MATA E FREITAS, 2008):

$$
\ln F_{i j t}=\alpha_{0}+\sum_{i=1}^{n} \beta_{k} \ln X_{k i j t}+\varepsilon_{i j t}
$$


Em que $\ln F_{i j t}$ é o log das receitas de exportação de $i($ Brasil $=i)$ para a economia $j$ no momento $t ; \ln X_{k}$ é a matriz de logs das variáveis explicativas; $\alpha_{0}$ é a constante; $n$ é o número de variáveis explicativas e $\varepsilon_{i j t}$ é o termo errático com as hipóteses do modelo clássico de regressão.

Os fluxos comerciais são as exportações dos capítulos 02 e 16 (carnes e miudezas, e preparações de carnes), capítulos 12 e 23 (sementes e oleaginosas, e resíduos de indústrias alimentares) e capítulo 24 (tabaco e seus sucedâneos manufaturados) da Nomenclatura Comum do Mercosul da Região Sul do Brasil. Como critério de categorização, utilizou-se o Sistema Harmonizado de dois dígitos (SH-2) de classificação de mercadorias. As variáveis explicativas empregadas no modelo foram escolhidas, conforme Mata e Freitas (2008), em linha com os postulados tradicionais da equação gravitacional e/ou a partir dos trabalhos relacionados com a identificação de determinantes das exportações agropecuárias brasileiras.

As diversas especificações do modelo empírico foram utilizadas e estimadas via mínimos quadrados ordinários em dados de painel. Essas especificações referem-se ao conjunto dos produtos da pauta agroexportadora brasileira. É igualmente válido incluir as características geográficas dos países porque elas têm efeitos importantes sobre os fluxos comerciais e são, em regra, não correlacionadas com outros determinantes da renda. Em outros termos, ainda que características geográficas não seja uma consequência da renda ou da política dos países, elas são fatores importantes para facilitar ou restringir fluxos e direções comerciais, sendo adotadas dummies de localização geográfica (MATA E FREITAS, 2008).

Ainda acerca da definição do método, Anderson e Van Wincoop (2003) resolvem os termos de resistência em função das variáveis observáveis e estimam o modelo gravitacional por mínimos quadrados não-lineares para minimizar a soma dos quadrados dos erros. Porém, um método alternativo é substituir os termos de resistência multilateral por dummies para os países da amostra. Esse método leva a estimativas consistentes dos parâmetros do modelo e, sua principal vantagem, é que essas estimativas podem ser conduzidas com abordagem de Mínimos Quadrados Ordinários - MQO.

O método de mínimos quadrados ordinários (MQO - Pooled) mostra-se bastante adequado para o presente trabalho, na medida em que o objetivo é medir o impacto de variáveis importantes nos fluxos de comércio internacional da Região Sul do Brasil, sob o âmbito das exportações de soja, tabaco e carnes, no período de 2000 a 2012.

As variáveis empregadas no presente estudo consideram a literatura existente dentro das prerrogativas da aplicação do modelo econométrico gravitacional e, as principais contribuições acerca do objeto de estudo, o qual aborda as exportações do setor agropecuário da Região Sul do Brasil junto ao mercado internacional e suas determinantes. Assim sendo, a equação é descrita como:

$$
\begin{gathered}
\ln _{i j t}=\alpha+\beta_{1} \operatorname{lndist}_{i j t}+\beta_{2} \operatorname{lnpib}_{j t}+\beta_{3} \operatorname{lnpop}_{j t}+\beta_{4} \operatorname{lnpsa}_{j t}+\beta_{5} \operatorname{lnpea}_{j t} \\
+\beta_{6} \operatorname{lnppr}_{j t}+\beta_{7} \operatorname{lnppc}_{i j t}+\beta_{8} \operatorname{lnpibper}_{i j}+\beta_{9} \text { Dfro }_{\text {Inp }} \text { In }_{i j t}
\end{gathered}
$$


Onde: $F_{i j t}$ são as exportações agropecuárias ou fluxos de comércio da Região Sul do Brasil para os países importadores; $\alpha$ é a constante do coeficiente de regressão; distijt é a distância da Região Sul do Brasil para o país importador (quilômetros em linha reta, do principal porto exportador do país/região); pib $b_{j t}$ é o produto interno bruto do país importador; $p_{j} p_{j t}$ é a população total do país importador; $p s a_{j t}$ é o percentual de participação do setor agrícola no produto interno bruto do país importador; pea $_{j t}$ é o percentual da participação das exportações agropecuárias nas exportações totais do país importador; $p r_{j t}$ é o percentual de participação da população rural no total da população do país importador; $p p c_{i j t}$ é a taxa de câmbio (Paridade Poder de Compra - PPC) entre a Região Sul do Brasil e a do país/região importador; pibper it é o produto interno bruto per capita da Região Sul do Brasil; fro/apc é a dummy para países importadores que fazem fronteira ou não, e que tem acordos preferenciais de comércio com a Região Sul do Brasil; $u_{i j t}$ termo de erro do modelo de regressão considerando os fluxos de comércio entre a Região Sul do Brasil e seu país/região importador.

No modelo de mínimos quadrados ordinários, variáveis são omitidas, o que implica que elas podem ir para o termo de erro. Para amenizar o problema, foram incluídas, no modelo, variáveis de efeito específicos facilmente observáveis, como a fronteira territorial, os acordos preferenciais de comércio e a distância. Deste modo, - MQO passa a ser um estimador eficiente, devido à propriedade de melhor estimador linear não-viesado (MORAIS, 2005).

As demais informações e fontes de consulta encontram-se: dist $t_{i j}$ - a disponibilidade dos dados encontra-se no sistema do United States Department of Agriculture (USDA); pib - é fonte de dados está disponível no World Bank; pop - $_{\text {- }}$ dados disponíveis no World Bank; $p s a_{j}$ - é a fonte de dados disponíveis no World Bank; pea - são os dados disponíveis no World Bank; $p p r_{j}$ - é a fonte de dados disponível no World Bank; $p p c_{i j}$ - fonte de dados disponíveis no International Monetary Fund (IMF); pibper $_{j}$ - fonte de dados disponível no World Bank e Instituto Brasileiro de Geografia e Estatística (IBGE); fro/apc - fonte de dados disponíveis no Instituto de Estudos do Comércio e Negociações Internacionais (ICONE).

Na próxima seção há uma breve caracterização da evolução do comércio agropecuário brasileiro, em particular da Região Sul do Brasil, inseridos dentro do comércio internacional, considerando os produtos soja, carnes e tabaco no período de 2000 a 2012, a seus principais mercados de destino, que no caso são a Argentina, China, Estados Unidos e União Europeia.

\section{Análise e Discussão dos Resultados}

A análise considerou a hipótese de que todos os coeficientes fossem constantes ao longo do tempo e entre países, desconsiderando-se as dimensões de tempo e espaço dos dados combinados (Pooled - MQO). Os resultados da regressão estimada para testar os fluxos de exportações do setor agropecuário da Região Sul 
do Brasil', para o período 2000 a 2012, com observações anualizadas para seus principais países importadores, encontram-se na Tabela 01.

A distância dos mercados compradores é a variável que exibe impacto individual negativo para as vendas de produtos do setor agropecuário da Região Sul do Brasil. Verifica-se que a variação da taxa de crescimento dos fluxos de exportação da Região Sul do Brasil para os principais países da amostra (Argentina, China, Estados Unidos e União Europeia) apresenta relação negativa e estatisticamente significativa a 10\%, sendo diferente de zero. Ou seja, um aumento de $1 \%$ na distância da Região Sul do Brasil para um de seus parceiros comerciais, equivale a uma queda de $0,951073 \%$ nas vendas de produtos do setor agropecuário da Região Sul do Brasil. Deste modo, quanto maior a distância entre as regiões, menor é a tendência a comerciar, corroborando com a hipótese do modelo de Newton (teoria da gravidade), adaptada a análise econômica, onde a distância entre dois corpos é inversamente proporcional ao comércio entre os países/regiões. Os resultados (ver Tabela 01) são semelhantes aos encontrados nos trabalhos de Tinbergen (1962), Anderson (1979), Bergstrand (1985 e 1989), Anderson e Van Wincoop (2003) e Mata e Freitas (2008).

Tabela 1. Resultados da regressão de dados em painel (Pooled - MQO) do modelo gravitacional das exportações agropecuárias da Região Sul do Brasil entre 2000/2012

\begin{tabular}{ccccc}
\hline SOURCE & SS & Df & MS & \\
\hline Model & 374053.05 & 9 & 41561.4499 & \\
Residual & 70002.2512 & 42 & 1666.72027 & \\
\hline Total & 444055.301 & 51 & 8706.96668 & \\
& & & & \\
\hline Exportações & Coef. & Std. Err. & $\mathbf{T}$ & 0.071 \\
\hline InDistância & $-0.951073^{* *}$ & 0.512657 & -1.86 & 0.059 \\
InPIB & $0.024163^{* *}$ & 0.011239 & 1.67 & 0.025 \\
InPIBpcSul & $0.0129718^{*}$ & 0.005592 & 2.32 & 0.029 \\
InPopulação & $0.6464372^{*}$ & 0.286154 & 2.26 & 0.125 \\
InPartAgPIB & 0.011915 & 0.007620 & 1.56 & 0.364 \\
InPExAgExp & -0.0054268 & 0.005913 & -0.92 & 0.166 \\
InPrtPopRur & 0.0050208 & 0.003561 & 1.41 & 0.050 \\
InIndTxCR & $0.7010917^{*}$ & 0.347912 & 2.02 & 0.585 \\
DFron/Apc & 0.3152904 & 0.572954 & 0.55 & 0.857 \\
Constante & 49.27819 & 271 & 0.18 &
\end{tabular}

Fonte: Resultado de pesquisa, elaborado pelo autor.

** Significância de $10 \%$.

* Significância de $5 \%$.

Tal indicativo representa que quanto maior for à distância entre os países, maiores serão os dispêndios envolvidos para que ocorram os fluxos de exportações. Conforme Azevedo e Graf (2013) a distância entre as nações gera um fator complicador ao comércio, pelo fato de quanto maior a distância entre ambos, maior os custos de transporte, aumentando os preços dos produtos a ser importados,

\footnotetext{
${ }^{1}$ Carnes - dos capítulos 02 e 16 (carnes e miudezas, e preparações de carnes); soja - capítulos 12 e 23 (sementes e oleaginosas, e resíduos de indústrias alimentares); e, fumo - capítulo 24 (tabaco e seus sucedâneos manufaturados), todos da Nomenclatura Comum do MERCOSUL, através de Sistema Harmonizado de dois dígitos (SH-2), da Região Sul do Brasil.
} 
levando os países a terem uma tendência natural de comércio com nações mais próximas, uma vez que a distância pode inviabilizar certas importações.

Em relação ao impacto do Produto Interno Bruto (PIB) dos países importadores sobre as exportações do setor agropecuário da Região Sul do Brasil, tal variável apresenta uma reação positiva, ou seja, a cada incremento de 1 ponto percentual do PIB do país importador, há um aumento de 0,024163\% nas vendas desses produtos da Região Sul do Brasil, estatisticamente significativa a 10\%. Tais resultados são semelhantes aos encontrados nos trabalhos de Sevela (2002), Zahniser et. al (2002), Mata e Freitas (2008), Souza (2009) e Azevedo e Graf (2013). Quanto maior o nível de riqueza/atividade econômica da nação importadora, evidenciada através do PIB, maior será a tendência a importar os produtos do setor agropecuário da região em questão. De acordo com este pressuposto, destacam-se nos países/região do modelo, os Estados Unidos e a União Europeia, os quais tem seu PIB na casa de US\$ 14,0 trilhões cada, aproximadamente, enquanto que Argentina e China respondem respectivamente por US\$ 4,5 trilhões e US\$ 280 bilhões, aproximadamente (valores de 2012).

Além disto, as exportações do setor agropecuário da Região Sul do Brasil também reagiram positivamente a incrementos na população dos parceiros comerciais envolvidos no estudo, identificados também nos trabalhos seminais da literatura econômica e, em Mata e Freitas (2008) e Azevedo e Graf (2013). Assim, o crescimento de $1 \%$ na população dos países compradores acarreta acréscimos de divisas de exportações do setor agropecuário na ordem de $0.6464372 \%$, estatisticamente significativos a $5 \%$. Observa-se que os países com maiores contingentes populacionais (com destaque para a China, com cerca de 1,35 bilhão de habitantes, a números de 2012), são comumente os que mais importam produtos do setor agropecuário, principalmente do "complexo soja".

Neste sentido, os resultados apresentados até aqui, corroboram com os estudos citados na seção três deste trabalho, onde é estabelecida uma regularidade dos fluxos comerciais, os quais são relacionados positivamente com as rendas e população do destino e negativamente com a distância entre eles. Quanto maior a renda e população dos países, maior a capacidade de comércio bilateral, mas, no entanto, a distância é inversamente proporcional a tal relação de comércio, ou seja, quanto maior a distância menor será o volume de comércio entre países.

Por outro lado, o Produto Interno Bruto per capita demonstrou efeito significativo a $5 \%$ na estimativa apresentada sobre o desempenho da economia da Região Sul do Brasil. De modo que a variação positiva de 1 ponto percentual na renda per capita representa um acréscimo de 0.0129718\% nas exportações de produtos do setor agropecuário. Este resultado demonstra o crescimento da renda através das exportações do setor agropecuário da Região Sul do Brasil. No trabalho de Mata e Freitas (2008), o resultado foi inverso, pois o crescimento da economia local mostrou-se um elemento limitante das exportações agropecuárias. Esta diferença entre as exportações do setor agropecuário da Região Sul do Brasil e o crescimento do PIB per capita local, pode ser relacionada à maior capacidade de resposta e maior habilidade de deslocamento de produção que o agronegócio da região sul tem desenvolvido, seja em função de maciços investimentos pregressos em tecnologia e manejo da produção (maior capacidade de resposta), seja pelo estabelecimento de cadeias de integração verticais e melhor conexão entre 
distribuidora de insumo, produtores in loco, processadores finais (deslocamento de produção) e, as estruturas de mercado (MATA E FREITAS, 2008).

Azevedo e Graf (2013) salientam que o tamanho das economias é um fator indispensável para explicar o volume comercializado entre duas nações, uma vez que a razão do PIB per capita do país exportador reflete seu potencial produtivo, sua capacidade de produção e investimento em novas tecnologias capazes de oferecer ao país uma maior competitividade, enquanto que o PIB do país importador reflete seu potencial de consumo, e a condição financeira que o país possui em adquirir e consumir produtos. Portanto, quanto maior o PIB de ambos, maior a tendência e o volume de comércio internacional.

Quanto ao perfil agroexportador dos parceiros comerciais, deve-se observar que, nas estimativas apresentadas, a participação da agropecuária no PIB dos países importadores e a participação de suas exportações agropecuárias nas exportações totais, são estatisticamente não significativas, ou seja, assumem o valor não diferente de zero. De acordo com os estudos de Mata e Freitas (2008), tais estimativas deveriam assumir um sinal negativo, referente aos fluxos de exportações do setor agropecuário da Região Sul do Brasil, visto que quanto maior a produção agropecuária e quanto maior o peso da mesma na economia do país importador, menor deveria ser a tendência a importar produtos agropecuários de outras regiões. Finalizando, países que são grandes produtores e vendedores de produtos agropecuários (tais como a China, União Europeia, Estados Unidos e Argentina), são, em relação aos três primeiros, grandes importadores líquidos de inúmeros produtos que não por acaso encabeçam a lista de produtos efetivamente exportados pela região sul, como carnes e soja.

Já a porcentagem da população rural na população total do país estrangeiro também é estatisticamente não significativa, o que demonstra o potencial do setor agropecuário do país importador (tal parâmetro deveria apresentar relação negativa). No entanto, apesar de possuir relativamente altos índices percentuais de população rural, tais países, principalmente a China e União Europeia, apresentam uma grande propensão a importar produtos agropecuários, visto que por questões estratégicas e técnicas (como área de produção, clima, custos de produção, entre outros) são especializados em determinados produtos, assim como a Região Sul do Brasil, é especializada na produção de carnes, tabaco e soja, para exportação.

Tabela 2. Estatísticas básicas da regressão de dados em painel (Pooled - MQO) do modelo gravitacional das exportações agropecuárias da Região Sul do Brasil

\begin{tabular}{cc}
\hline Number of obs & 52 \\
\hline $\mathbf{F}(\mathbf{9}, \mathbf{4 2})$ & 24.94 \\
\hline Prob $\mathbf{F}$ & 0.0000 \\
\hline R-squared & 0.8424 \\
\hline Adj R-squared & 0.8086 \\
\hline Root MSE & 40.825 \\
\hline
\end{tabular}

Fonte: Resultado de pesquisa, elaborado pelos autores.

As estimações referentes à taxa de câmbio real entre a Região Sul do Brasil e os países importadores, é positiva e estatisticamente significativa a $5 \%$, ou seja, a cada 1 ponto percentual de crescimento da taxa real de câmbio, reflete um aumento de $0.7010917 \%$ nas exportações de produtos do setor agropecuário. Deste modo, no 
caso do câmbio, uma desvalorização da moeda local exibiu um impacto positivo sobre as vendas do setor agropecuário ao exterior. Portanto, como explicitado, quanto mais desvalorizado o câmbio frente à moeda externa do país importador, maior será a propensão a exportar e, comumente maior será a renda gerada pela pauta agroexportadora da Região Sul.

Quanto a variável dummy para país fronteiriço e com Acordos Preferenciais de Comércio (APC), no caso a Argentina, tal parâmetro não foi estatisticamente significativo, ou seja, assume o valor não diferente de zero (o país em questão assumiu valor 1 , enquanto que os outros países/regiões assumiram o valor 0 ). Para tal parâmetro esperava-se uma relação positiva aos fluxos comerciais. Como encontrado em Mata e Freitas (2008), o local de identificação do país traduz-se numa menor atração dos produtos agropecuários ofertados pela Região Sul do Brasil no mercado internacional. Esse resultado esta provavelmente associada a estruturas produtivas substitutas nesses bens (caso de carnes, cereais e leguminosas), ou mesmo por hábitos alimentares distintos. Azevedo e Graf (2013), argumentam que quando os países, importador ou exportador, possuem fronteiras e APC, há uma forte tendência natural de comércio bilateral entre ambos.

Quanto ao $R^{2}$ do modelo gravitacional, estimado em dados em painel, por mínimos quadrados ordinários (Pooled) apresentados sinteticamente na Tabela 02, demonstra um valor de 0.8424 , que corresponde a um alto índice de determinação, no entanto, esta estimação não é muito diferente dos outros trabalhos, que também apresentam um $R^{2}$ elevado, tais como os trabalhos de Sevela (2002), Zahniser et. al (2002), Mata e Freitas (2008) e Azevedo e Graf (2013), que correspondem respectivamente a 0.8152; 0.9224; 0.73; e, 0.6625 .

No Quadro 03, está elencado o resumo dos resultados principais encontrados pela literatura econômica acerca da aplicação do modelo gravitacional sobre a análise das exportações agropecuárias no Brasil, bem como seus métodos de estimação e suas aplicações.

Quadro 3. Resumo dos principais resultados estimados pela literatura com a aplicação do modelo gravitacional a análise das exportações agropecuárias no

\begin{tabular}{|c|c|c|c|c|}
\hline \multicolumn{5}{|c|}{ Brasil } \\
\hline Autores & Produtos & & tados & Estimação \\
\hline \multirow{3}{*}{ Castilho (2001) } & \multirow{3}{*}{ Carnes, açúcar e vinhos. } & Dist. & -1.253 & \multirow{3}{*}{ Efeito Fixo } \\
\hline & & PIB & 0.708 & \\
\hline & & Pop. & - & \\
\hline \multirow{3}{*}{$\begin{array}{l}\text { Mata e Freitas } \\
\quad(2008)\end{array}$} & \multirow{3}{*}{$\begin{array}{l}\text { Carnes, soja, café, açúcar, } \\
\text { suco de laranja e algodão. }\end{array}$} & Dist. & -2.5613 & \multirow{3}{*}{ MQO } \\
\hline & & PIB & 0.7327 & \\
\hline & & Pop. & 0.3788 & \\
\hline \multirow{3}{*}{ Wilson (2009) } & \multirow{3}{*}{ Café, chá e cacau. } & Dist. & -1.35 & \multirow{3}{*}{ Efeito Fixo } \\
\hline & & PIB & 0.61 & \\
\hline & & Pop. & - & \\
\hline \multirow{3}{*}{ Campos et. al (2012) } & \multirow{3}{*}{ Carne bovina. } & Dist. & -2.2181 & \multirow{3}{*}{ Tobit } \\
\hline & & PIB & 1.5881 & \\
\hline & & Pop. & 1.1423 & \\
\hline
\end{tabular}

Fonte: Elaborado pelos autores.

Enfim, os resultados encontrados atestam e ratificam os trabalhos principais, ou seja, as premissas básicas do modelo de gravidade, o qual corresponde dizer-se 
que em uma regularidade de fluxos comerciais, estes são relacionados positivamente com as rendas e população de destino e negativamente com a distância entre eles. A metodologia utilizada (modelo de gravidade) atendeu as regras básicas do modelo, sendo que sua aplicação seguiu os propósitos empíricos dos trabalhos seminais da literatura econômica.

\section{Notas Finais}

A equação da gravidade foi usada com sucesso por muitos pesquisadores para explicar os fluxos de comércio bilateral entre países, e que ao longo do tempo foi sendo aprimorada. Mesmo o modelo apresentando um grande poder explicativo do comércio bilateral, até o início da década de 1990, possuía uma grande resistência entre os pesquisadores, especialmente pela ausência de um maior embasamento teórico. No entanto, o aumento do interesse pelo modelo gravitacional trouxe consigo um maior embasamento teórico ao modelo, proporcionando um crescimento de sua credibilidade.

Portanto, como resultados principais, foram confirmados os estudos empíricos acerca do objeto em questão, que parte da premissa básica da "Lei Gravitacional de Newton", adaptada para a literatura econômica. Na segunda metade do século XX, Isard (1960), Tinbergen (1962), Linneman (1966), Anderson (1979) e, Bergstrand (1985), perceberam que o volume de comércio entre dois países pode ser previsto, com razoável precisão, pela equação gravitacional, que conforme Coelho (1982) é caracterizada pela massa de dois corpos (países), representadas por renda e população, os quais são inversamente proporcionais à distância entre os mesmos.

Neste sentido, considerando o modelo proposto no respectivo trabalho, proveniente de Mata e Freitas (2008), a variável relativa à distância entre a Região Sul do Brasil e seus países importadores, demonstrou na estimação efeito negativo sobre as exportações do setor agropecuário, de mesmo modo que as variáveis população e renda (PIB) dos países importadores apresentaram relação positiva frente aos fluxos do comércio do setor agropecuário. De acordo com Mata e Freitas (2008), observou-se que os países com maiores contingentes populacionais e com maior nível de atividade econômica, em termos de PIB, são os que importam mais produtos do setor agropecuário da região Sul do Brasil. Ou seja, a equação da gravidade aplicada cumpre com a premissa apresentada ao longo da pesquisa.

Vale ressaltar que, a distância é um fator preponderante nos níveis de comércio internacional, visto que pela equação da gravidade, verifica-se o fator restritivo desta variável nos fluxos comerciais. Isto, apesar do encurtamento dos mercados mundiais resultante da globalização vivenciada.

Quanto às demais variáveis, demonstra-se que o produto interno bruto per capita e a taxa de câmbio real também influenciam positivamente ao montante de exportações do setor agropecuário da Região Sul do Brasil, frente aos países importadores (no caso do câmbio, uma desvalorização da moeda local exibiu um impacto positivo sobre as vendas do setor agropecuário ao exterior). E, a participação da agropecuária no PIB de seus países importadores, a participação de suas exportações agropecuárias nas exportações totais, a participação da população rural na população total e, a variável dummy para país fronteiriço e com 
APC, são não significativas. Tais indicadores revelariam a autonomia daqueles países de destino no que se reporta a sua autossuficiência na produção de alimentos e, a variável dummy, a localização geográfica (fronteira e APC), que revelaria uma maior propensão a comerciar dada as condições locacionais e políticas.

\section{REFERÊNCIAS}

AITKEN, N. D. The effect of the EEC and EFTA on European trade: a temporal crosssection analysis. The American Economic Review, v. 63, n. 5, p. 881-892, 1973.

ANDERSON, J. E. A theoretical foundation for the gravity equation. American Economic Review. V. 69, n. 1, p. 106-116, 1979.

ANDERSON, James E.; WINCOOP, V. Erik. Gravity with Gravitas: A Solution to the Border Puzzle, NBER Working Paper, No 8079, Cambridge Mass.: National Bureau of Economic Research, 2003.

ANDERSON, James E.; WINCOOP, V. Erik. Trade costs. Boston College Working Papers in Economics, 593. Boston, 2004.

AZEVEDO, A. F. Z. de. $O$ efeito do Mercosul sobre o comércio: uma análise com o modelo gravitacional. Pesquisa e Planejamento Econômico, v. 34, p. 307-339, 2004.

AZEVEDO, A. F. Z. de; PORTUGAL, M. S.; BARCELLOS NETO, E P. Impactos comerciais da área de livre comércio das Américas uma aplicação do modelo gravitacional. Revista Economia Contemporânea, Rio de Janeiro, v.10, n.2, p.237267, 2006.

AZEVEDO, A. F. Z.; REIS, M. O impacto da criação do Mercosul no fluxo de comércio bilateral: uma abordagem com o modelo gravitacional. Universidade do Vale do Rio dos Sinos- UNISINOS. São Leopoldo, 2006.

AZEVEDO, A. F. Z.; GRAF, C. O. Comércio bilateral entre os países membros do Mercosul: uma visão do bloco através do modelo gravitacional. Economia Aplicada, v. 17, n. 1, p. 135-158. 2013.

BALTAGI, B. D. Econometric analysis of panel data. 3 ed. Nova York: John Wiley and Sons, 2005.

BERGSTRAND, J. H. The Gravity equation in international trade: some microeconomic foundations and empirical evidence. Review of Economics and Statistics, n. 67, v. 3, p. 474-481, 1985.

BERGSTRAND, J. H. The generalized gravity equation monopolistic competition, and the factor proportions theory in international trade. Review of Economics and Statistics, n. 71, p. 143-153, 1989. 
BRADA, J. C.; MÉNDEZ, J. A. Economic integration among developed, developing and central planned economies: a comparative analysis. The Review of Economics and Statistics, v. 67, n. 4, p. 549-556, 1985.

BURNQUIST, H. L.; BARROS, G. S. C.; BACCHI, M. R. P. Estimação de equações de Oferta de Exportação de Produtos Agropecuários para o Brasil (1992/2000). Brasília: IPEA, 2002. 53 p. (Texto para Discussão, 875).

BURNQUIST, H. L.; SOUZA, M. J. P. de. Facilitação de Comércio e Impactos sobre o Comércio Bilateral. Estudos Econômicos, v. 41, n. 1, São Paulo: jan-Mar. 2011 p. 91118.

CAMPOS, A. C.; BRAGA, M. J.; SCHWANTES, F. Efeitos das barreiras geográficas e comerciais sobre as exportações brasileiras de carne bovina (1996-2007). Teoria e Evidência Econômica - Ano 18, n. 38, p. 9-33, jan./jun, 2012.

CARVALHO, A.; DE NEGRI, J. A. Estimação de equações de importação e exportação de Produtos Agropecuários para o Brasil (1977/1998). Brasília: IPEA, 1999. 30 p. (Textos para Discussão, 698).

CASTILHO, M. R. (2001). $O$ acesso das exportações do Mercosul ao mercado europeu. In: XXIX ENCONTRO NACIONAL DE ECONOMIA, Salvador, Anais. Salvador: ANPEC, 2001.

CHENG, I. H.; WALL, H. J. Controlling for heterogeneity in gravity models of trade integration. Working Paper 99-010A. Saint Louis: Federal Reserve Bank of Saint Louis, 2002.

COELHO, J. Dias. Formulação em programação matemática do modelo gravitacional e sua interpretação econômica. WorkingPaper $n^{\circ} 2$. Faculdade de Economia, Universidade Nova de Lisboa, Campo Grande: 1982.

DEADORFF, Alan V. Testing Trade Theories and Predicting Trade Flows Handbook of International Economics, Volume 1, Amsterdam: North-Holland, 1995.

DEARDOFF, A. V. Determinants of bilateral trade: does gravity work in a neoclassical world? In: The Regionalization of the World Economy (Ed. JEFFREY A. FRANKEL). Chicago: Chicago University Press, 1998. EVENETT, S. J.; KELLER, W. On Theories Explaining the Success of the Gravity Equation. Journal of Political Economy, v. 110, n. 2, p. 281-316, 2002.

EVENETT, Simon J.; KELLER, Wolfgang. On Theories Explaining the Success of the Gravity Equation NBER Working Paper, No W6529, Cambridge Mass.: National Bureau of Economic Research, 2002.

FAO. FAOSTAT. Disponível em:<//http:www.fao.org/>. Acesso em agosto de 2013. 
FARIAS, J. J. de; HIDALGO, A. B. Comércio Interestadual e Comércio Internacional das Regiões Brasileiras: uma Análise Utilizando o Modelo Gravitacional.

Documentos Técnico-Científicos da Universidade Federal de Pernambuco, vol. 43, $\mathrm{n}^{\circ}$ 02. Recife, 2012. p. 251-266.

FEENSTRA, R. C.; Understanding the home market effect and the gravity equation: the role of differentiating goods. NBER Working Paper, 6804. 2002.

FEENSTRA, R. C.; Advanced international trade: theory and evidence. New Jersey: Princeton University Press, 2004.

FEENSTRA, R. C.; MARKUSEN, J. R.; ROSE, A. K. Using the gravity equation to differentiating among alternative theories of trade. The Canadian Journal of Economics, v. 34, n. 2, p. 430-477, 2001.

FONSECA, M. B.; HIDALGO, A. B. A formação da ALCA e os prováveis efeitos sobre as exportações agrícolas brasileiras. Revista de Economia e Sociologia Rural, v. 44, n. 1, p. 9-26, 2006.

HELPMAN, Elhanang. International Trade in the Presence of Product Differentiation, Economies of Scale and Monopolistic Competition: A Chamberlin Heckscher-Ohlin Approach. Journal of International Economics, 11, 1987, pp. 305340.

HELPMAN, Elhanang. Monopolistic Competition in Trade Theory. Frank Graham Memorial Lecture, Special Paper 16, International Finance Section, Princeton University, Princeton, N.J., 1989.

HIDALGO, A. B.; VERGOLINO, J. R. O nordeste e o comércio inter-regional e internacional: um teste dos impactos por meio do modelo gravitacional. Economia Aplicada, v. 2, n. 4, p. 707-725, 1998.

INSTITUTO DE PESQUISA ECONÔMICA APLICADA (IPEA). Disponível em: <http://http://www.ipeadata.gov.br/>. Acesso em: out. 2012.

INSTITUTO BRASILEIRO DE GEOGRAFIA E ESTATÍSTICA (IBGE). Disponível em: <http://seriesestatisticas.ibge.gov.br/>. Acesso em: out. 2012.

INTERNATIONAL MONETARY FUND (IMF). Disponível em: <http://www.imf.org/external/index.htm>. Acesso em: 25 out. 2012.

ISARD, W. Methods of regional analysis: an introduction to regional Science. MIT Press. Cambridge, Massachusetts, 1960.

KRUGMAN, Paul. Geography and Trade. Cambridge: MIT Press, 1991, 136 p. 
KRUGMAN, Paul. Increasing Returns and Economic Geography. Journal of Political Economy, Vol.3, 1991, pp. 483-499.

KRUGMAN, Paul; OBSTFELD, P. Economia Internacional. Pearson/Prentice Hall. 2010.

LEAMER, E. E.; STERN, R. M. Quantitative international economics. Chicago, IL: Aldine, 1970.

LINNEMANN, Hans. An Econometric Study of International Trade Flows. Amsterdam: North-Holl and Publishing Company, 1966.

MATA, Daniel \& FREITAS, Rogério. Produtos Agropecuários: Para quem exportar?. Revista de Economia e Sociologia Rural. Piracicaba, SP, vol. 46, nº2, 2008. p. 257290.

MCCALLUM, J. National Borders Matter: Canada U.S. Regional Trade Patterns, American Economic Review, June 1995, 85(3), p. 615-623.

MINISTÉRIO DO DESENVOLVIMENTO INDÚSTRIA E COMÉRCIO EXTERIOR (MDIC). Aliceweb. Brasília: MDIC. Disponível em: <http://aliceweb.mdic.gov.br/>. Acesso em: 23 ago. 2012.

MORAIS, Adriano Giacomini. Criação e desvio de comércio no Mercosul e no Nafta. Dissertação (Mestrado - Universidade de São Paulo), São Paulo, 2005.

NEGRI, J. A. de; CARVALHO, A. Estimação de Equações de Importação e Exportação de Produtos Agropecuários para o Brasil (1977/1998). Revista Econômica do Nordeste, v. 30, n. Especial, Fortaleza, 1999. p. 504-523.

PASS, Tiiu. European integration and eu eastward enlargement process in international trade: using a gravity approach for exploring bilateral trade flows. The 42nd Congress of the European Regional Science Association. Germany, Dortmund, 2002.

PIANI, G.; KUME, H. Fluxos bilaterais de comércio e blocos regionais: uma aplicação do modelo gravitacional. Rio de Janeiro: IPEA, jul. 2000. 22 p. (Texto para Discussão, n. 749).

POYHONEN, Pentty. A Tentative Model for Volume in Trade Between Countries. Weltwirtschaftliches Arhiv, Vol. 90, 1963, p. 91-113.

REIS, J. N. P.; CRESPO, J. E. Q. Um modelo econométrico para as exportações de açúcar do Brasil. Agricultura em São Paulo, São Paulo, v. 45, n. 1, p. 17-32, 1998.

TINBERGEN, Jan. Shaping the World Economy. New York: Twentieth Century Fund, 1962. 
UNITED NATIONS (UN). Growth in United Nations Membership, 1945-

2005.Disponível em: <http://www.un.org/overview/growth.htm>. Acesso em: 14 jun. 2012.

USDA. United States Department of Agriculture. Disponível em: <http://www.usda.gov/wps/portal/usda/usdahome>. Acessoem: 20 out. 2012.

WILSON, N. Examining the effect of certain customs and administrative procedures on trade. Overcoming border bottlenecks: the costs and benefits of trade facilitation. OECD - Trade policy studies. Paris, 2009.

WORLD BANK. Disponível em: <http://www.worldbank.org/pt/country/brazil >. Acesso em: 22 out. 2012. WORLD TRADE ORGANIZATION (WTO). Regional Trade Agreements: facts and figures. Bruxelas: World Trade Organization. Disponível em: <http://www.wto.org/english/tratop_e/region_e/regfac_e.htm>. Acesso em: 12 jul. 2012.

ZAHNISER, S.; PICK, D.; POMPELLI, G. M.; GEHLHAR, M. J. Regionalism in the western hemisphere and its impact on U.S. agricultural exports: a gravity-model analysis. American Journal of Agricultural Economics, v. 84, n. 3, p. 791-797, 2002.

Daniel Claudy da Silveira. Doutor pelo Programa de Pós-Graduação em Desenvolvimento Regional (PPGDR) da Universidade de Santa Cruz do Sul (UNISC); Mestre pelo Programa de Pós-Graduação em Economia e Desenvolvimento (PPGE\&D) pela Universidade Federal de Santa Maria (UFSM); Professor Assistente do Curso de Ciências Econômicas do Departamento de Ciências Administrativas, Contábeis, Econômicas e da Comunicação (DACEC/UNIJUí). daniel.silveira@unijui.edu.br

Paulo Ricardo Feistel. Doutor em Economia pela Universidade Federal de Pernambuco (UFPE), Professor Associado do Departamento de Economia e do Programa de Pós-Graduação em Economia e Desenvolvimento (PPGE\&D) da Universidade Federal de Santa Maria (UFSM).prfeistel@gmail.com

Argemiro Luís Brum. Doutor em Economia pela L'ecole Des Hautes Etudes En Sciences Socieles (LHESS-França), Professor Adjunto do Departamento de Ciências Administrativas, Contábeis, Econômicas e da Comunicação (DACEC) e do Programa de Pós-Graduação em Desenvolvimento Regional (PPGDR) da Universidade Regional do Noroeste do Estado do Rio Grande do Sul (UNIJUÍ). argelbrum@unijui.edu.br

Como citar: CLAUDY DA SILVEIRA, Daniel; FEISTEL, Paulo Ricardo; BRUM, Argemiro Luís. As Exportações da Região Sul do Brasil: Uma Análise do Setor Agropecuário. Redes (St. Cruz Sul, Online), Santa Cruz do Sul, v. 24, n. 3, p. 272-294, set. 2019. ISSN 1982-6745. doi: https://doi.org/10.17058/redes.v24i3.12330. 